Rapid Communications

\title{
Voltammetric Response of Phenylboronic Acid Monolayer-modified Gold Electrode to Sugars
}

\author{
Shigehiro TaKahashi, Yoshitomo KaShiwagi, Tomonori Hoshi, and Jun-ichi ANZaI ${ }^{\dagger}$ \\ Graduate School of Pharmaceutical Sciences, Tohoku University, Aramaki, Aoba-ku, Sendai 980-8578, Japan
}

\begin{abstract}
The surface of a gold $(\mathrm{Au})$ disk electrode was modified with a self-assembled monolayer consisting of phenylboronic acid moiety to fabricate a voltammetric sensor sensitive to sugars. The modified Au electrode exhibited a voltammetric response to sugars in the presence of $\mathrm{Fe}(\mathrm{CN})_{6}{ }^{3-}$ ion in the sample solution at neutral $\mathrm{pH}$. The peak current of the cyclic voltammograms decreased depending on the type and concentration of sugars. The dynamic range of the electrode is 3 $100 \mathrm{mM}$ for glucose and mannose and $1-30 \mathrm{mM}$ for fructose. The sugar sensor can be used repeatedly after rinsing in $10 \mathrm{mM}$ acetate buffer ( $\mathrm{pH} 4.5)$.
\end{abstract}

(Received April 5, 2004; Accepted April 12, 2004)

Phenylboronic acids (PBA) are known to bind sugars in an aqueous and organic media. ${ }^{1}$ Based on the PBA-sugar binding, many kinds of PBA derivatives whose absorption or emission spectra are sensitive to sugar have been synthesized for the spectroscopic determination of sugars..$^{2-4}$ These methods, however, rely on a homogeneous system in an aqueous or nonaqueous solution, where PBA derivatives are added in the sample solution as reagent. On the other hand, from the viewpoint of the development of sugar sensors, PBA derivatives should be immobilized on the surface of transducers. In this context, carbon and metal electrodes have been modified with PBA-containing polymers such as poly(acrylate), ${ }^{5}$ poly(aniline), ${ }^{6}$ and poly(pyrrole). ${ }^{7}$ Self-assembled monolayers of PBA have also been used for developing electrochemical and optical sugar sensors. ${ }^{8-10}$ We report here a preliminary result on the voltammetric response of PBA monolayer-modified $\mathrm{Au}$ electrode to glucose, mannose, and fructose. The peak current in the cyclic voltammogram was found to be sensitive to the adsorption of sugars on the electrode surface. The data show that the PBA monolayer-modified Au electrode may be promising as an electrochemical sensor for sugar sensing.

\section{Experimental}

Dithiobis(4-butyrylamino-m-phenylboronic acid) (DTBA-PBA) was prepared from 3-aminophenylboronic acid hemisulfate (Nacalai Tesque, Kyoto, Japan) and 4,4-dithiodibutyric acid (Tokyo Kasei, Tokyo, Japan) using 1-ethyl-3-(3dimethylaminopropyl)carbodiimide $\mathrm{HCl}$ (Nacalai Tesque, Kyoto, Japan) as catalyst according to the reported procedure. ${ }^{9}$ All reagents used are commercial products of highest grade available.

The surface of a mirror-polished Au disk electrode $(3 \mathrm{~mm}$ diameter) was cleaned in a $0.5 \mathrm{M} \mathrm{H}_{2} \mathrm{SO}_{4}$ solution by scanning the potential from -0.2 to $1.5 \mathrm{~V}$ vs. $\mathrm{Ag} / \mathrm{AgCl}$ at a scan rate of

\footnotetext{
† To whom correspondence should be addressed.

E-mail: junanzai@mail.pharm.tohoku.ac.jp
}

$0.1 \mathrm{~V} \mathrm{~s}^{-1}$ for $20 \mathrm{~min}$. The cleaned Au electrode was immersed in a DTBA-PBA solution $\left(0.4 \mathrm{mg} \mathrm{mL}^{-1}\right.$ in $9: 1$ mixture of tetrahydrofuran and methanol) for $8 \mathrm{~h}$ at room temperature ( $c a$. $20^{\circ} \mathrm{C}$ ) to preparing the self-assembled PBA monolayer on the surface of the Au electrode (Fig. 1).

Cyclic voltammetry was carried out at room temperature using a potentiostat (NPGFZ-2501-A, Nikko Keisoku, Atsugi, Japan) in a conventional three-electrode cell consisting of the PBA monolayer-modified Au electrode as a working electrode, a platinum wire as a counter electrode, and an $\mathrm{Ag} / \mathrm{AgCl}$ (3 M $\mathrm{KCl})$ reference electrode. The electrochemical measurements were carried out at room temperature $\left(\mathrm{ca} .20^{\circ} \mathrm{C}\right)$.

\section{Results and Discussion}

The surface coverage of the DTBA-PBA monolayer on the modified electrode was evaluated from the reductive desorption of the DTBA-PBA monolayer. ${ }^{11}$ The reduction peak in the cyclic voltammogram $(\mathrm{CV})$ for the DTBA-PBA monolayermodified electrode was observed at $c a .-0.9 \mathrm{~V}$ in the $0.5 \mathrm{M}$ $\mathrm{KOH}$ solution, confirming that the DTBA-PBA was immobilized on the Au surface through an sulfur-Au bonding as illustrated in Fig. 1. The surface coverage of DTBA-PBA was calculated from the reduction current to be $2.3 \times 10^{-10} \mathrm{~mol} \mathrm{~cm}^{-2}$ based on the true surface area of the electrode determined by the reported procedure. ${ }^{12}$
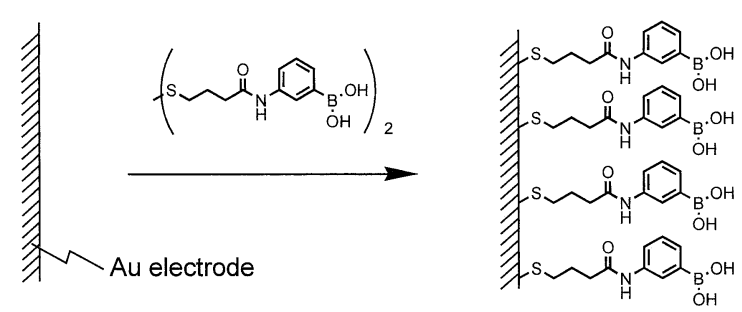

Fig. 1 Preparation of DTBA-PBA monolayer-modified $\mathrm{Au}$ electrode. 


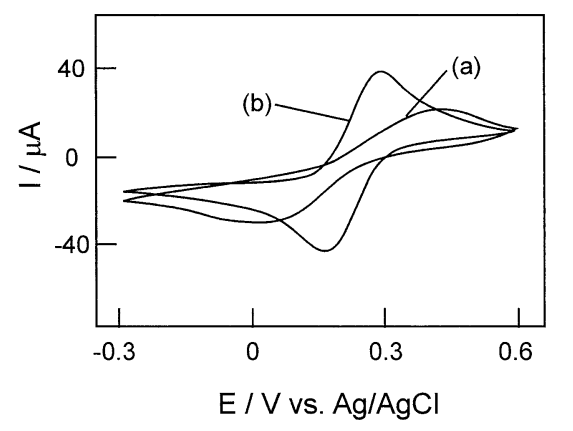

Fig. 2 Cyclic voltammograms of the DTBA-PBA monolayermodified electrode in the presence (a) and absence of $50 \mathrm{mM}$ fructose (b) in a $10 \mathrm{mM}$ phosphate buffer containing $5 \mathrm{mM} \mathrm{K}_{3}\left[\mathrm{Fe}(\mathrm{CN})_{6}\right]$ and $100 \mathrm{mM} \mathrm{KCl} \mathrm{(pH} \mathrm{7.6).} \mathrm{Scan} \mathrm{rate;} 50 \mathrm{mV} \mathrm{s}^{-1}$.

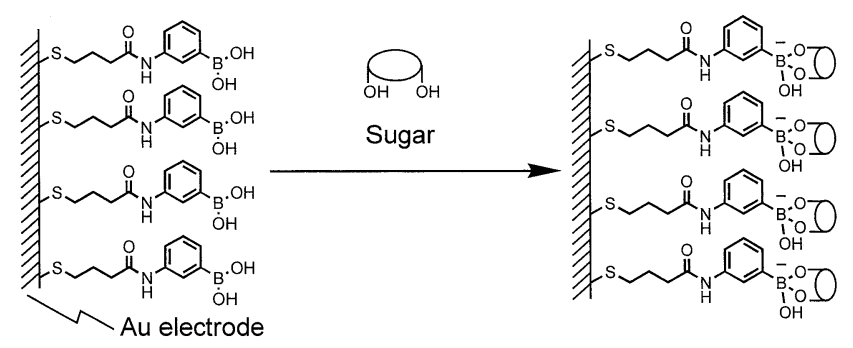

Fig. 3 The binding of sugar on the surface of the DTBA-PBA monolayer accompanied with the addition of $\mathrm{OH}^{-}$ion.

Figure 2 shows $\mathrm{CVs}$ of the PBA monolayer-modified $\mathrm{Au}$ electrode in the $10 \mathrm{mM}$ phosphate buffer containing $5 \mathrm{mM}$ $\mathrm{K}_{3}\left[\mathrm{Fe}(\mathrm{CN})_{6}\right]$ and $100 \mathrm{mM} \mathrm{KCl}(\mathrm{pH} \mathrm{7.6)}$. In the absence of sugar $(\mathrm{CV} b)$, the $\mathrm{CV}$ exhibited clear redox peaks originating from the electrochemical redox reaction of $\left[\mathrm{Fe}(\mathrm{CN})_{6}\right]^{3-}$ ion. The oxidation and reduction peaks are observed at 275 and $150 \mathrm{mV}$, respectively. Thus, the potential difference between the oxidation and reduction peaks, $\Delta E_{\mathrm{p}}$, is $125 \mathrm{mV}$. On the other hand, to evaluate the effects of sugar, the $\mathrm{CV}$ was measured in the same buffer solution containing $5 \mathrm{mM} \mathrm{K}_{3}\left[\mathrm{Fe}(\mathrm{CN})_{6}\right]$ in the presence of $50 \mathrm{mM}$ fructose in the solution $(\mathrm{CV}$ a). We used here fructose as a model substrate because fructose is known to be strongly bound to PBA derivatives. ${ }^{1-4}$ The peak current $\left(i_{\mathrm{p}}\right)$ in the CV decreased significantly and the $\Delta E_{\mathrm{p}}$ increased to $c a$. $400 \mathrm{mV}$ in the presence of fructose. The fructose-dependent voltammetric behavior can be rationalized based on the formation of PBA-fructose adduct on the surface of the DTBAPBA monolayer modified electrode. It is reasonable to assume that, at the neutral $\mathrm{pH}$, the PBA moieties on the electrode bind fructose to form the negatively charged surface as a result of the addition of $\mathrm{OH}^{-}$ion from the solution (Fig. 3). ${ }^{2-4}$ Consequently, the access of the $\left[\mathrm{Fe}(\mathrm{CN})_{6}\right]^{3-}$ anion to the electrode surface was suppressed severely due to the electrostatic repulsion, resulting in the deteriorated $\mathrm{CV}$. The voltammetric results clearly show that the $\mathrm{CV}$ can be used for the electrochemical determination of fructose in the solution. Thus we employed the $i_{\mathrm{p}}$ value as an output signal for the voltammetric sugar sensing in the present study.

It is known that PBA derivatives and their sugar adduct accept $\mathrm{OH}^{-}$ion to form the negative forms depending on the $\mathrm{pH}$ in the media. ${ }^{1-4}$ Usually, $\mathrm{p} K$ values of PBA-sugar adducts for the $\mathrm{OH}^{-}$ addition are more acidic than those of the parent PBA. These facts suggest that the voltammetric response of the DTBA-PBA

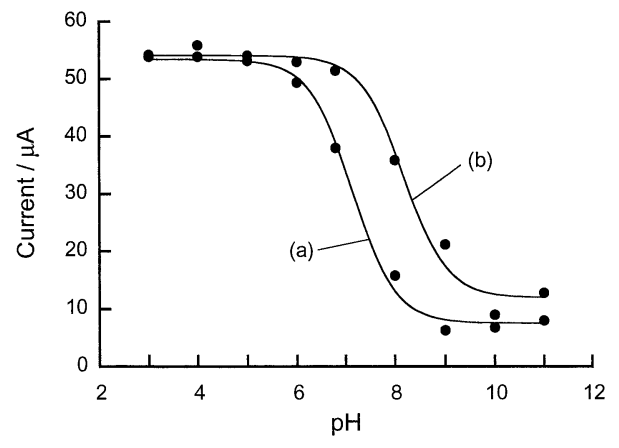

Fig. 4 The effect of $\mathrm{pH}$ on the peak currents of the DTBA-PBA monolayer-modified electrode in the presence (a) and absence of 50 $\mathrm{mM}$ fructose (b) in the solution. The CVs were measured in buffer containing $5 \mathrm{mM} \mathrm{K}_{3}\left[\mathrm{Fe}(\mathrm{CN})_{6}\right]$ and $100 \mathrm{mM} \mathrm{KCl}$ at a scan rate of 50 $\mathrm{mV} \mathrm{s}^{-1}$.

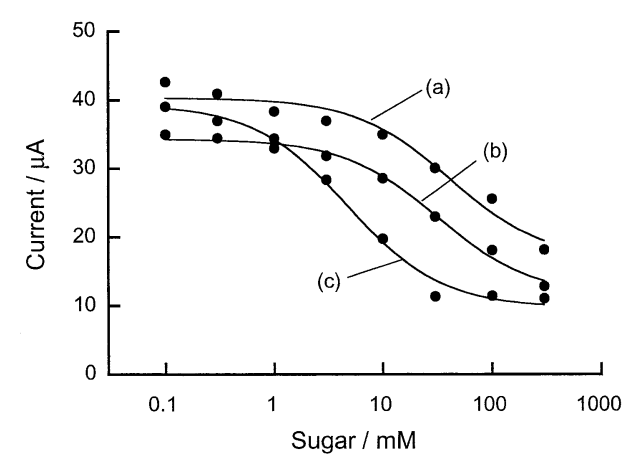

Fig. 5 The calibration graphs for glucose (a), mannose (b), and fructose (c).

monolayer modified electrode is also $\mathrm{pH}$ dependent. For this reason, we evaluated the response of the electrode to fructose as a function of $\mathrm{pH}$. Figure 4 plots the $i_{\mathrm{p}}$ values of the electrode in the $5 \mathrm{mM} \mathrm{K}_{3}\left[\mathrm{Fe}(\mathrm{CN})_{6}\right]$ solution in $\mathrm{pH} 3-11$. The $i_{\mathrm{p}}$ values measured in the basic solutions were smaller than those obtained in the acidic solutions for both in the presence and absence of fructose, confirming the negative charges on the DTBA-PBA surface as the origin of the voltammetric response. It is clear that, for the voltammetric sensing of sugars, one has to obtain the $\mathrm{CV}$ data at neutral $\mathrm{pH}$ where the $i_{\mathrm{p}}$ of the sugartreated electrode is smaller than before the sugar treatment. Judging from the data in Fig. 4, use of the $\mathrm{K}_{3}\left[\mathrm{Fe}(\mathrm{CN})_{6}\right]$ solution of pH 7-8 may be recommended for effecting a high sensitivity.

Figure 5 shows calibration graphs for glucose, mannose, and fructose. The dynamic range of the electrode is $3-100 \mathrm{mM}$ for glucose and mannose and $1-30 \mathrm{mM}$ for fructose. The high sensitivity for fructose is in line with the high affinity of fructose to PBA derivatives. ${ }^{1-4}$

We tested the reusability of the DTBA-PBA monolayer modified electrode. The sugar-PBA adduct formed on the electrode surface was dissociated to regenerate the sugar-free PBA monolayer by treating the sugar-bound electrode in a 10 $\mathrm{mM}$ acetate buffer $(\mathrm{pH} \mathrm{4.5)}$ for $10 \mathrm{~min}$ at room temperature. The original $\mathrm{CV}$ was obtained after this treatment and the electrode can be used repeatedly.

Thus, we have demonstrated the usefulness of the DTBAPBA monolayer modified electrode for voltammetric sugar sensing. The studies for optimizing the operating variables such as $\mathrm{pH}$ and ionic strength of the sample solution, the concentration of $\left[\mathrm{Fe}(\mathrm{CN})_{6}\right]^{3-}$ ion, and the type of the buffer used 
for surface renewal are now in progress in this laboratory.

\section{References}

1. T. D. James, K. R. A. S. Sandanayake, and S. Shinkai, Angew. Chem. Int. Ed. Engl., 1996, 35, 1911.

2. N. DiCesare and J. R. Lakowicz, Tetrahedron Lett., 2001 , 42,9105 .

3. S. Gao, W. Wang, and B. Wang, Bioorg. Chem., 2001, 29, 308.

4. J. N. Camara, J. T. Suri, F. E. Cappuccio, R. A. Wessling, and B. Singaram, Tetra. Lett., 2002, 43, 1139.

5. A. Kikuchi, K. Suzuki, O. Okabayashi, H. Hoshino, K. Kataoka, Y. Sakurai, and T. Okano, Anal. Chem., 1996, 68,
823.

6. E. Shoji and M. S. Freund, J. Am. Chem. Soc., 2002, 124, 12486.

7. M. Nicolas, B. Fabre, and J. Simonet, Electrochim. Acta, 2001, 46, 1179

8. H. Murakami, H. Akiyoshi, T. Wakamatsu, T. Sagara, and N. Nakashima, Chem. Lett., 2000, 940.

9. N. Kanayama and H. Kitano, Langmuir, 2000, 16, 577.

10. M. Lee, T.-I. Kim, K.-H. Kim, J.-H. Kim, M.-S. Choi, H.-J. Choi, and K. Koh, Anal. Biochem., 2002, 310, 163.

11. C. A. Widrig, C. Chung, and M. D. Porter, J. Electroanal. Chem., 1991, 310, 335.

12. J. F. Rodriguez, T. Mebrahtu, and M. P. Soriaga, J. Electroanal. Chem., 1987, 233, 283. 